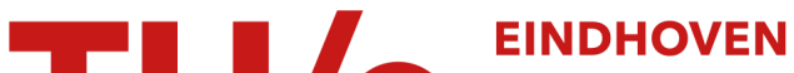 \\ UNIVERSITY OF \\ TECHNOLOGY
}

\section{Communicating emotions in expressive avatars}

Citation for published version (APA):

Kierkegaard, P. M. (2010). Communicating emotions in expressive avatars. International Journal of Intercultural Information Management, 2(1), 16-23. https://doi.org/10.1504/IJIIM.2010.030707

DOI:

10.1504/IJIIM.2010.030707

Document status and date:

Published: 01/01/2010

\section{Document Version:}

Publisher's PDF, also known as Version of Record (includes final page, issue and volume numbers)

\section{Please check the document version of this publication:}

- A submitted manuscript is the version of the article upon submission and before peer-review. There can be important differences between the submitted version and the official published version of record. People interested in the research are advised to contact the author for the final version of the publication, or visit the $\mathrm{DOI}$ to the publisher's website.

- The final author version and the galley proof are versions of the publication after peer review.

- The final published version features the final layout of the paper including the volume, issue and page numbers.

Link to publication

\section{General rights}

Copyright and moral rights for the publications made accessible in the public portal are retained by the authors and/or other copyright owners and it is a condition of accessing publications that users recognise and abide by the legal requirements associated with these rights.

- Users may download and print one copy of any publication from the public portal for the purpose of private study or research.

- You may not further distribute the material or use it for any profit-making activity or commercial gain

- You may freely distribute the URL identifying the publication in the public portal.

If the publication is distributed under the terms of Article $25 \mathrm{fa}$ of the Dutch Copyright Act, indicated by the "Taverne" license above, please follow below link for the End User Agreement:

www.tue.nl/taverne

Take down policy

If you believe that this document breaches copyright please contact us at:

openaccess@tue.nl

providing details and we will investigate your claim. 


\title{
Communicating emotions in expressive avatars
}

\section{Patrick Kierkegaard}

School of Computer Science and Electronic Engineering, University of Essex,

Wivenhoe Park, Colchester, Essex CO4 3SQ, UK

E-mail: patrick@patrickonline.net

\begin{abstract}
Avatars have become a fundamental part of collaborative virtual environments. They are the visual embodiment of the user and are designed to address key issues in the interaction process between the user and the CVE. Giving avatars expressive abilities has been considered essential in computer-human reaction. Having an avatar, which has the ability to express facial expressions, as a part of the computer interface increases human performance. Researches have provided strong evidence that emotions can be effectively portrayed visually in avatars to represent human users in collaborative virtual environments. These include manipulation of facial expressions as they are efficient carriers of emotions. However, avatars have still only limited variations in their emotional expressions to become believable entities.
\end{abstract}

Keywords: avatars; collaborative environment; CVE; collaborative virtual environments; emotions; facial gesture; intercultural information management.

Reference to this paper should be made as follows: Kierkegaard, P. (2010) 'Communicating emotions in expressive avatars', Int. J. Intercultural Information Management, Vol. 2, No. 1, pp.16-23.

Biographical note: Patrick Kierkegaard is a Doctoral student at the Department of Computing and Electronic Systems, University of Essex. He is researching on brain-computer interface and computer games for disabled and locked-in patients.

An earlier version of this article was published in Int. J. Liability and Scientific Enquiry (Inderscience), Vol. 2, No. 1, 2009, pp.103-109.

\section{Introduction}

Virtual worlds are maybe the future of human interactions and communications in collaborative environment. Computer designers, who created these thriving virtual worlds, have discovered a much more attractive way to use the internet: through an avatar. The use of avatars is a fundamental part of collaborative virtual environment (CVE), a virtual space where users are represented by the 3D image 'avatar'. There have been many CVEs created recently for different purposes, such as recreational, industrial training and education and each of the CVEs has avatars for users to use in navigating 
through the 3D space as they interact with one another. Avatars have been successfully introduced into web pages and internet chats.

An avatar, derived from the Sanskrit word for one regarded as an incarnation, serves as a physical representation for the user. An avatar is a virtual object representing the participant in the virtual world (Fraser et al., 2003). They are digital models driven by real-time humans. The first image-like avatar representations were the emoticons - alphanumeric symbols that receive a certain iconic and image-like structure - which were used to indicate a reaction, stance or gesture by the user to things happening in the text field (Rivera, Cooke and Bauhs, 1996) and used widely today as smileys.

In virtual environments, people may communicate and setup social spaces through the utilisation of avatar proxies. When a user enters an immersive environment, his/her presence is revealed as an avatar representation. This representation is crucial to other users in the 3D world because it serves as a unique form of identity and existence.

In all of the major virtual worlds, one can spend an extraordinarily long time at this first stage, choosing the appearance of the avatar as well as its abilities. Depending on the universe, the user can freely, within the confines of the world's 'realities', select sex, appearance, profession and physical features (Damer, 1998). The avatars fall into several categories based on appearance. Some of the more common avatar classes include animal representations, cartoon characters and abstract avatars which may have shocking or unusual form.

As defined above, the avatar is the representation of the self in a given physical environment. This environment creates an idealised situation in which a player may freely shape her own 'self'. She has full control over her own image. It is significant to note that people talking about their activities use the pronoun 'I', each identifying his or her 'self' with their avatar they have created (Filiciak, 2003).

In a universe that offers hundreds of virtual worlds, the virtual body becomes a vessel of choice, and the thinking part of humanity - the Self - will find it convenient to slip into and out of avatars as economic, social and political circumstances dictate (Huhtamo, 1995). The avatar representation fulfils several important functions:

- the visual embodiment of the user

- means of interaction with the world

- means of sensing various attributes of the world.

As the visual embodiment of the user, avatars provide the opportunity to change the inner self in a way that does not require high cost therapies. No one knows who the person behind the avatar really is. This anonymity is helpful and can be used as a guide to improve aspects of the 'self'. Because the user has to write down his thoughts to communicate with other avatars, he becomes attuned to his emotions. Through interactions and positive feedback from other avatars, one can gain confidence in his self-discovery. Thus, using avatars is also a form of therapy. One of the areas in which one would expect avatars to be of use is in the treatment of social anxiety. Avatars can elicit the kind of fear people experience in social situations, which will thus encourage patients to expose their fears. Very often, patients hesitate to express their fears to people. By using virtual humans that are capable of some form of interaction, speech and have the ability to recognise and emit typical nonverbal social communication via facial expressions and hand/body gesture cues, certain anxiety disorders can be targeted (Heimberg et al., 1993). 
Developing avatars to deal with social anxieties has been attempted by some scientists. Mel Slater and his colleagues developed avatars to deal with patients suffering from social anxiety caused by fear of public discourse. These avatars displayed a variety of human emotions and behaviours. They have reported on an experiment designed to assess the anxiety responses of people giving $5 \mathrm{~min}$ presentations to virtual audiences consisting of eight male avatars (Pertaub, Slater and Barker, 2002). The presenters faced three different types of audience behaviour: (a) an emotionally neutral audience that remained static throughout the talk, (b) a positive audience that exhibited friendly and appreciative behaviour toward the speaker; (c) a negative audience that exhibited hostile and bored expressions throughout the talk. A Personal Report of Confidence as a Public Speaker instrument was used to measure the participants' responses and the latter was found to be immensely affected by the negative audience. The study concluded that when people in a secluded, empty room give a talk to a virtual audience, their response is affected by the behaviour of that audience, even though they know it to be virtual.

Avatars are also designed to address key issues in the interaction process between the user and the CVE, such as the identity, accessibility and the status of the owner, and the avatar functions and characteristics. Therefore, in many cases there is a psychological relationship between the user and their avatar (Craven et al., 2002).

Useful applications of avatars have been also investigated for several domains of human interaction (e.g. Morris, Pelphrey and McCarthy, 2005) and communication (e.g. De Leo et al., 2003; Grammer and Oberzaucher, 2006). Bailenson et al. (2003) demonstrated that humans develop an experience of being with another person when confronted with avatars. According to $\mathrm{Ku}$ et al. (2005), avatars have the potential to influence their subject's emotions dependent on gender of the avatar and intensity of expression.

Their use becomes even more important in networked virtual environments as participants' representation is used for communication. According to Capin et al. (1997) and Benford et al. (1997), the avatar representation functions to provide:

- perception (to see if anyone is around)

- localisation (to see where the other person is)

- identification (to recognise the person)

- visualisation of others' interest focus (to see where the person's attention is directed)

- visualisation of other's actions (to see what the other person is doing and what is meant through gestures)

- social representation of self through decoration of the avatar (to know what the other participants' task or status is).

By using avatars, realism is achieved with these functionalities. In essence, using an avatar representation enables the user to apply his own real world experience, by providing the direct relationship between how the user control the avatar in the virtual world and how the avatar moves related to this control. Avatars can also help the users to understand the context of the conversation, including the involved personalities and their social relationship towards each others. They help users identify other participants and hence make it easy to follow the discussion in a collaborative setting. 


\section{Interplay between emotions and avatars in collaborative environments}

There is a growing plethora of literature that deals with the interplay between emotions, avatar and collaborative environments. Several papers have been published on the virtual and communicative functions of avatars. Bente et al. (2004) has shown that even avatars with very minimal levels of behaviour realism elicit responses from others. Gillies and Slater (2005) has developed a co-relational non-verbal behaviour in virtual characters enabling the behaviour of the character to correlate realistically with that of the real person.

Giving avatars expressive abilities has been considered beneficial as it potentially leverages the observer's real life experience with social interaction (Cowell and Stanney, 2005). From the real world, emotions of others influence us in our decisions and our own emotional state (Picard, 1997). Argyle (1988) argued that the expression of emotions in the face or the body is a part of the wider system of natural human communication that has evolved to facilitate social life and whenever one interacts with another person, that other person's emotional expressions are monitored and interpreted. The introduction of emotional expressiveness in avatars can aid interpersonal communication in the collaborative environment. In Takeuchi and Nagao's study (1993), the participants interacted with a prototype computer system where they could ask about the prices and functions of computer products during a $10 \mathrm{~min}$ period. While interacting with the participants the computer system either showed facial displays for each situation or it expressed the situation verbally. The results of this study showed that the conversations between the individuals and the system capable of facial displays were more successful than the conversations they had with the system with short phrases.

The embodiments of the participants through avatars also enable the participants to use body language and facial expressions in their messages. There are several ways of expressions for avatars: body, hands, voices, gestures and gazing. These include manipulation of facial expressions as they are efficient carriers of emotions. For the purpose of this essay, the discussion will be limited to facial expressions.

The body and facial language are largely influenced by personality and they either look or behave like the users they represent. Cheng, Farnham and Stone (2002) found that people in a text and graphics shared VE preferred representations of themselves and demonstrated that people's habits and preferences will shape avatar appearance.

The human face is considered to be an independent channel of communication that helps to coordinate conversations in human-human interactions. Although the human face is only a small part of a person's body, it has an important function in communication. Faces provide clues to the state of human emotions or even to read lips. Ekman, Friesen and Ellsworth (1972) identified six universal facial expressions corresponding to the following emotions: surprise, anger, fear, happiness, disgust/contempt and sadness. Researchers have also examined to a lesser degree such states as pain, fatigue, alertness, boredom, interest, attention, flirtation, deception and post-problem solving. These various emotions and states are of particular relevance for humans in the course of face-to-face social communication and the capacity for people to recognise them in computer generated avatars.

The studies in the field of human-computer interaction suggest that having an avatar which has the ability to express facial expressions, as a part of the computer interface, increases human performance. Walker, Sproull and Subramani (1994) compared the responses of the subjects who participated in a computer-based interview survey where 
the questions were either presented in a text format or spoken by a talking face. Experimental results showed that the participants interacted with the talking face during the survey spent more time, made fewer mistakes and wrote more comments compared to the participants who answered the text-based questions. Nagao and Takeuchi (1994) assert that facial expressions serve two functions; as expressions of emotional states, or as communicative signals. Chovil (1991) said that the primary function of facial displays is to communicate messages and emotion to others as the human face can be seen as an independent channel that conveys emotional and conversational signals encoded as facial displays. Another use for facial display is to help develop better social relations as facial displays are usually directed not at oneself, but at others (Takeuchi and Nagao, 1993).

Facial expressions and body gestures indicate the mood of the person and his virtual representation. The navigation of the participants, and therefore their interests, is seen by others. The most common facial actions are the raising or lowering of brows, and widening or tightening of the eyes - thus adding to the realism of the experience. Thus, the avatar representation simulates the presence of each user in the virtual environment. They elicit the experience of being with another person.

The recent exploration on the role of emotions in human-computer interaction have produced various studies and investigations on the use of facial expressions of emotions as means of non-verbal communications in CVEs. Marc Fabri, David Moore and D. Hobbs of Leeds Metro University have published the results of several experimental studies investigating the introduction of emotional expressiveness using avatars as the interaction device. Their research focused largely on how facial expressions affect the participants 'experience'.

Gaze is also a richly informative behaviour in face-to-face interaction (Kendon, 1967; Argyle, 1988) and serves the following functions: regulating conversations flow, providing feedback, communicating emotional information, communicating the nature of interpersonal relationship and avoiding distraction by restricting visual input. Garau et al. (2001) conducted an experiment designed to investigate the importance of eye gaze in humanoid avatars representing people engaged in conversation and found that an avatar whose gaze behaviour is related to the conversation would improve the quality of communication compared to one whose gaze behaviour is random.

Believability is an important factor for avatar design. Avatars should express their emotions consistently through all modalities available to them to ensure high believability (Gong, 2000). Becker et al. (2005) have created an empathic embodied agent that expresses affect while playing a card game with a human user. They hypothesise that the believability of the character can be increased through the addition of negative emotion expression by the character. Other systems try to increase believability by reacting to the affective state of the user. Prendinger, Dohi and Ishizuka (2004) have created an animated interface agent that escorts the user during a virtual job interview. The agent obtains affective information from the user and displays empathic behaviour accordingly.

Several aspects must be considered in order to represent the emotional state of the user. Culture is an important aspect which needs to be incorporated. While researchers do acknowledge the importance of adding cultural dimensions to embodied agents, few have actually implemented them. As many cultures differ in their ways to express and perceive emotion, these aspects also must be identified in order to design and implement avatars that express the appropriate emotional reactions and intensity levels of those reactions by 
a more natural and plausible way to which users can relate (Ekman, Friesen and Ellsworth, 1972).

\section{Conclusions}

Humans have a wide array of emotional expression and unfortunately, avatars have only limited variations in their emotional expressions to become believable entities. Unfortunately, avatars still play a minor role in the communication that takes place in the virtual world. Communication is still often done entirely through email exchanges and skype. The most probable cause for this result is due to the graphically poor avatars which are unable to display rich facial and gestured behaviour (Salem and Earle, 2000).

The researches have provided strong evidence that emotions can be effectively portrayed visually in avatars to represent human users in collaborative virtual environments. If avatars are to become a major wave in online communications, it is important to develop avatars that are highly realistic with real time facial form and tracking. More researches are needed on the use of simple but distinctive clues in expressing the emotional state of CVE inhabitants through their avatars to make them believable.

\section{References}

Argyle, M. (1988) Bodily Communication. London: Methuen \& Co.

Bailenson, J., Bloscovich, A., Beall, C. and Loomis, J. (2003) 'Interpersonal distance in immersive virtual environments', Personality and Social Psychology Bulletin, Vol. 29, pp.819-833.

Becker, H., Prendinger, Ishizuka, M. and Wachsmuth, I. (2005) 'Evaluating affective feedback of the $3 \mathrm{~d}$ agent max in a competitive card game', in J. Tao, T. Tan and R. Picard (Eds), First International Conference on Affective Computing and Intelligent Interaction (pp.466-473). Berlin: Springer.

Benford, S., Bowers, J., Fahlen, L.E., Greenhalgh, C. and Snowdon, D. (1997) 'Embodiments, avatars, clones and agents for multi-user, multi-sensory virtual worlds', Multimedia System, Vol. 5, pp.93-104.

Bente, G., Ruggenberg, S., Tietz, B. and Wortberg, S. (2004) 'Measuring behavioural correlates of social presence in virtual encounters', Paper presented in the Proceedings of the 5th Annual Conference of the International Communication Association.

Capin, T.K., Pandzic, I., Noser, H., Thalmann, N. and Thalmann, D. (1997) 'Virtual human representation and communication in VLNET networked virtual environment', IEEE Computer Graphics and Applications, Vol. 17, pp.42-53.

Cheng, L., Farnham, S. and Stone, L. (2002) 'Lessons learned: building and deploying shared virtual environments', in R. Schroeder (Ed.), The Social Life of Avatars: Presence and Interaction in Shared Virtual Environments (pp.19-39). London: Springer.

Chovil, N. (1991) 'Discourse-oriented facial displays in conversation. University of British Columbia', Research on Language and Social Interaction, Vol. 25, pp.163-194.

Cowell, A. and Stanney, K. (2005) 'Manipulation of non-verbal interaction style and demographics embodiments to increase anthromorphic computer character credibility', Int. J. Human Computer Studies, Vol. 62, pp.281-306.

Craven, M., Benford, S., Greenhalgh, C., Wyver, J., Brazier, C.J., Oldroyd, A. and Regan, T. (2000) 'Ages of avatar', ACM proceedings of the third international conference on collaborative virtual environments, September, pp.189-194. 
Damer, B. (1998) Avatars. Berkeley, CA: Peachpit Press.

De Leo, G., Ponder, M., Molet, T., Fato, M., Taíman, D., Magnenatr-Thalmann, N., Bermano, F. and Beltrame, F. (2003) 'A virtual reality system for the training of volunteers involved in health emergency situations', Cyberpsychological Behaviour, Vol. 6, pp.267-274.

Ekman, P., Friesen, W. and Ellsworth, P. (1972) Emotion in the Human Face: Guidelines for Research and Integration of Findings. New York, NY, USA: Pergamon Press Inc.

Filiciak, M. (2003) 'Hyperidentities - post-modern identity patterns in massively multiplayer online role-playing games', in M.J.P. Wolf and B. Perron (Eds), The Video Game Theory Reader. London, UK: Routledge, pp.87-102.

Fraser, M., Hindmarsh, J., Benford, S. and Heath, C. (2003) 'Getting the picture: enhancing avatar representations in collaborative virtual environments', in D. Snowdon, E. Churchill and E. Frecon (Eds), Inhabited Information Spaces, pp.33-150.

Garau, M., Skater, M., Bee, S. and Sasse, M. (2001) 'The impact of eye gaze on communication using humanoid avatars', Paper presented in the Proceedings of the CH1 2001, 31 March-5 April.

Gillies, M. and Slater, M. (2005) 'Non-verbal communication for correlational characters', Paper presented in the Proceedings of the 8th Annual International Workshop Presence.

Gong, L. (2000) 'What makes a natural language interface natural?', Paper presented in the Proceedings of the Language Processing workshop in CHI2000.

Grammer, K. and Oberzaucher, E. (2006) 'The reconstruction of facial expressions in embodied systems: new approaches to an old problem', ZIF Mitteilungen, Vol. 2, pp.14-31.

Heimberg, R.G., Salzman, D.G., Holt, C.S. and Blendell, K.A. (1993) 'Cognitive-behavioral group treatment for social phobia: effectiveness at five-year follow-up', Cognitive Therapy and Research, Vol. 17, pp.325-339.

Huhtamo, E. (1995) 'Encapsulated bodies in motion: simulators and the quest for total immersion', in. S. Penny (Ed.), Critical Issues in Electronic Media. Albany, NY: State University of New York Press, pp.159-186.

Kendon, A. (1967) 'Some functions of GAZE-direction in social interaction', Acta Psychologica, Vol. 26, pp.22-63.

Ku, H.J., Jang, K.U., Kim, S.H., Park, J.H., Lee and Kim, J.J. (2005) 'Experimental results of affective valence and arousal to avatar's facial expressions', Cyber psychology Behaviour, Vol. 8, pp.493-503.

Morris, J., Pelphrey, K. and McCarthy, G. (2005) 'Regional brain activation evoked when approaching a virtual human on a virtual walk', Journal of Cognitive Neuroscience, Vol. 17, pp.1744-1752.

Nagao, K. and Takeuchi, A. (1994) 'A speech dialogue with facial displays: multimodal human-computer conversation', Paper presented in the Proceedings of the 32nd Annual Meeting of the Association for Computational Linguistics, Las Cruces, NM, June 1994.

Pertaub, D.P., Slater, M. and Barker, C. (2002) 'An experiment on public speaking anxiety in response to three different types of virtual audience', Presence: Teleoperators and Virtual Environments, Vol. 11, pp.68-78.

Picard, R. (1997) Affective Computing. Cambridge, MA: The MIT Press.

Prendinger, H., Dohi, H. and Ishizuka, M. (2004) 'Empathic embodied interfaces: addressing users' affective state', in J. Tao, T. Tan and R. Picard (Eds), Tutorial and Research Workshop on Affective Dialogue Systems (pp.53-64). Berlin: Springer.

Rivera, K., Cooke, N. and Bauhs, J. (1996) 'The effects of emotional icons on remote communications', Paper presented in the Proceedings of the CHI'96.

Salem, B. and Earle, N. (2000) 'Designing a non-verbal vocabulary for expressive avatars, collaborative virtual environments CVE 2000', Paper presented in the Proceedings of the $A C M$, San Francisco, CA, USA, 10-12 September 2000. 
Takeuchi, A. and Nagao, K. (1993) 'Communicative facial displays as a new conversational modality. Human factors in computing systems', Paper presented in the Proceedings of the INTERCHI '93, Amsterdam, Netherlands, April, pp.187-193.

Walker, J., Sproull, L. and Subramani, R. (1994) 'Using a human face in an interface', in B. Adelson, S. Dumais and J. Olson (Eds), Paper presented in the Proceedings of the $A C M$ Conference on Human Factors in Computing Systems CHI'94, ACM Press, NY, pp.85-91. 